\title{
Chiara Gambacorti, Sade: une esthétique de la duplicité. Autour des romans historiques sadiens
}

\section{Marisa Ferrarini}

\section{(2) OpenEdition}

1 Journals

\section{Edizione digitale}

URL: http://journals.openedition.org/studifrancesi/1354

DOI: $10.4000 /$ studifrancesi. 1354

ISSN: 2421-5856

\section{Editore}

Rosenberg \& Sellier

\section{Edizione cartacea}

Data di pubblicazione: 1 décembre 2015

Paginazione: 595

ISSN: 0039-2944

\section{Notizia bibliografica digitale}

Marisa Ferrarini, «Chiara Gambacorti, Sade: une esthétique de la duplicité. Autour des romans historiques sadiens», Studi Francesi [Online], 177 (LIX | III) | 2015, online dal 01 décembre 2015, consultato il 10 janvier 2021. URL: http://journals.openedition.org/studifrancesi/1354 ; DOI: https://doi.org/10.4000/ studifrancesi.1354

Questo documento è stato generato automaticamente il 10 janvier 2021.

\section{(c) $(1) \ominus$}

Studi Francesi è distribuita con Licenza Creative Commons Attribuzione - Non commerciale - Non opere derivate 4.0 Internazionale. 


\title{
Chiara Gambacorti, Sade: une esthétique de la duplicité. Autour des romans historiques sadiens
}

\author{
Marisa Ferrarini
}

\section{NOTIZIA}

CHIARA GAMBACORTI, Sade: une esthétique de la duplicité. Autour des romans historiques sadiens, Paris, Classiques Garnier, 2014 («L'Europe des Lumières», 30), pp. 504.

1 Prendendo spunto dal suggerimento-invito pubblicato fa Michel Delon nella «Préface» al primo volume delle Euvres di Sade, di suddividere la produzione sadiana in testi essoterici o esoterici, secondo il loro grado di decenza o di pornografia, l'autrice mostra come il versante sovversivo del Marchese si celi in realtà nei suoi testi più anodini, a partire dal loro funzionamento interno: rispetto o violazione del patto di lettura. Sotto il discorso moralizzatore del narratore/autore, è possibile reperire un discorso antitetico che ne sovverte i valori. "Ce double discours axiologique», sostiene Chiara Gambacorti, definisce un'estetica della duplicità (p.18) che ci viene presentata come una grande invenzione sadiana. Peccato che l'autrice non conosca i testi secenteschi che l'hanno teorizzata, in particolare il trattato Della dissimulazione onesta (1641) di Torquato Accetto, dove addirittura il messaggio dello scrittore si nasconde nei silenzi, nelle cesure e nelle cicatrici che si è imposto!

2 Va però riconosciuto a Chiara Gambacorti il merito di aver preso in esame i tre romanzi sadiani (La Marquise de Gange, Adélaïde de Brunswick, Isabelle de Bavière) che la critica aveva sino ad ora trascurati. Tutti e tre sono stati scritti a Charenton, negli ultimi anni di vita del marchese (molto probabilmente tra il 1807 e il 1813), a testimonianza della sua attività letteraria in quel periodo; tutti e tre sono romanzi storici che rivelano un rapporto ambiguo e complesso con la Storia e la scrittura della Storia. Costituiscono, quindi, un corpus omogeneo e interessante per l'analisi dell'estetica della duplicità. 
Il metodo applicato è ineccepibile: procedere anzitutto a un'analisi testuale minuziosa, che sola può permettere di cogliere i meccanismi della scrittura sadiana e mettere in luce i diversi procedimenti testuali (strategie narrative, artifici di stile, ecc.) «qui ébranlent sourdement l'apparente orthodoxie morale et religieuse des ouvrages étudiés» (p. 23). Procedere poi a una contestualizzazione storico-letteraria delle opere prese in esame per stabilire, da un lato, l'originalità del progetto estetico e romanzesco di Sade rispetto alla riflessione estetica e alla produzione romanzesca dell'epoca, dall'altro l'originalità e le implicazioni etiche ed estetiche della scrittura sadiana della Storia, rispetto alle fonti storiche e letterarie da cui lo scrittore prende ispirazione.

4 Lo studio si articola in tre parti, ognuna delle quali è dedicata a un romanzo (nel presunto ordine cronologico di redazione) ed è composta di tre capitoli, preceduti da una prefazione e seguiti da una conclusione. Né i capitoli, né le introduzioni e le conclusioni che li accompagnano sono strutturati allo stesso modo e riguardano le stesse problematiche. Risulta pregevole il dialogo incessante che l'autrice stabilisce tra $\mathrm{i}$ tre romanzi storici e le altre opere sadiane.

Un'osservazione può tuttavia essere fatta a Chiara Gambacorti: quando si pubblica una tesi di dottorato (sostenuta nel 2012 dalla candidata) presso una casa editrice prestigiosa come i Classiques Garnier, è opportuno dichiararlo e magari evitare quelle ripetizioni e quei costrutti accademici che, tipici e quasi necessari in lavori di quel genere, rischiano, in un'opera destinata ad un pubblico più vasto, di appesantire inutilmente la lettura di un'opera che avrebbe invece meritato e tratto vantaggio da una redazione più snella e lineare. 